\title{
Relationship between Microstructure and Notch Tensile Strength in Ti-15V-3Cr-3Sn-3Al Alloy at Elevated Temperatures
}

\author{
Rong-Tan Huang*1, Wen-Han Chen*2 and Leu-Wen Tsay \\ Institute of Materials Engineering, National Taiwan Ocean University, Keelung, 20224, Taiwan, R. O. C.
}

The notch tensile strength (NTS) of Ti-15V-3Cr-3Sn-3Al (Ti-15-3) aged at temperatures ranging from 426 to $600^{\circ} \mathrm{C}$ was determined at elevated temperatures, and correlated to microstructure. Notch tensile tests were conducted in laboratory air at the room temperature, 150,300 and $450^{\circ} \mathrm{C}$. The base metal specimen aged at $426^{\circ} \mathrm{C}$ formed elongated $\alpha$ precipitates interlocked in a basket-weave like structure and then had peak hardness but inferior notch tensile strength at room temperature due to the trans-granular quasi-cleavage fracture seperated along the $\alpha / \beta$ interface in the aged specimen. As the aging and test temperature increased, the coarse Widmanstätten $\alpha$ in the specimen aged at $540^{\circ} \mathrm{C}$ was facilitated to perform high NTS owing to crack deflection or microcrack formation in Ti-15-3 alloy under $300^{\circ} \mathrm{C}$, while the improved ductility and notch blunting of the specimen aged at $426^{\circ} \mathrm{C}$ reduced the notch brittleness and resulted in a remarkably improved NTS tested at $450^{\circ} \mathrm{C}$. The NTS of the specimen aged at $426^{\circ} \mathrm{C}$ was much higher than that of the other aged specimen tested at $450^{\circ} \mathrm{C}$. This result suggested that the basket-weave-like structure was more resistant to the softening of substance than the coarse Widmansttäten structure at $450^{\circ} \mathrm{C}$. [doi:10.2320/matertrans.M2012306]

(Received September 3, 2012; Accepted December 10, 2012; Published February 1, 2013)

Keywords: titanium-15vanadium-3chromium-3aluminum-3tin, microstructure, notch tensile strength, fracture

\section{Introduction}

Ti-15V-3Cr-3Sn-3Al (hereafter Ti-15-3) alloy, developed during the 1970's on an Air Force contract and later scaled up to produce titanium strip, is one of the most practically used $\beta$-titanium alloys and offer an attractive combination of strength, toughness and fatigue resistance in heavy section. ${ }^{1)}$ With an excellent cold deformability in the proper $\beta$ solution treatment and a high strength after $\alpha$ precipitation aging, the cold-formable and age-hardenable alloy is used in a variety of airframe applications, in many cases as an alternative to Ti$6 \mathrm{Al}-4 \mathrm{~V}^{2}{ }^{2}$ Several studies have shown that the strength and ductility of Ti-15-3 can be enhanced through thermo or thermomechanical processing (TMP). ${ }^{3-7)}$ It is known that the strengthening of Ti-15-3 alloys can be achieved by the precipitation of uniformly dispersed fine $\alpha$-phase in the $\beta$ matrix. ${ }^{8)}$ Typically, at aging temperatures higher than $450^{\circ} \mathrm{C}$, $\alpha$ precipitation first occurs preferentially at $\beta$ grain boundaries and subsequently, intragranular $\alpha$ precipitation appears in a single step aging after solution treatment. ${ }^{7)}$ Also, at lower aging temperature 300 to $450^{\circ} \mathrm{C}$, fine $\alpha$ aggregates are formed uniformly within $\beta$ grains by nucleating at precursory isothermal $\omega$ particles. ${ }^{7)}$ In general, the strength of Ti-15-3 and the volume fraction of the $\alpha$ phase decrease with aging temperature increased in the over-aged condition. ${ }^{4)}$ Moreover, coarsening of Widmanstätten $\alpha$ structure is beneficial to achieve high fracture toughness due to the crack branching or crack deflection in Ti-15-3 alloy. ${ }^{9)}$ Additionally, the notch tensile strength (NTS) is known to decrease with increasing $\beta$ grain size of Ti-15-3 alloy, while the fracture toughness increases as the $\beta$ grain size increases. ${ }^{10)}$

Titanium alloys have been widely used in the applications of aerospace and military industries at the temperature often below $550^{\circ} \mathrm{C}$. It is reported that beta titanium alloys are characterized by a ductile-brittle transition with increasing

\footnotetext{
${ }^{* 1}$ Corresponding author, E-mail: rthuang@mail.ntou.edu.tw

${ }^{* 2}$ Graduate Student, National Taiwan Ocean University
}

temperature. ${ }^{11,12)}$ Thus, the maintenance of high NTS at elevated temperature is necessary for the alloy to avoid premature cracking/failure in service. The presence of sharp notches or stress concentrations in a material, however, can increase the likelihood of cracking or sensitivity under tensile straining. ${ }^{13,14)}$ It was reported that a crack nucleating in triaxial tensile field ahead of a notch may cause failure if the local stress intensity reaches the fracture toughness of the material. ${ }^{15)}$ The fracture toughness is concerned with the engineering design and life estimation of the materials and structures in aircraft industries, and sharp notch tensile testing is found to be an alternative method to evaluate the fracture toughness of materials. ${ }^{16}$ ) However, in the open literature, few works have been concentrated on the NTS of Ti-15-3, particularly at elevated temperature. In previous studies, sharp notch specimens were utilized to investigate the effect of microstructure on the notch sensitivity of titanium alloys and welds. ${ }^{17-20)}$ Accordingly, the purpose of this study is to investigate the effect of microstructure on the NTS of Ti-15-3 at elevated temperatures, and the relationship between microstructure and notch tensile fracture is also discussed.

\section{Experimental Procedure}

The as-received Ti-15-3 alloy, purchased from Hwa-Chu Co., with a thickness of $3 \mathrm{~mm}$ was used in the experiment. The chemical composition in weight percent of the alloy was $3.05 \mathrm{Al}, 2.92 \mathrm{Cr}, 2.99 \mathrm{Sn}, 15.1 \mathrm{~V}, 0.071 \mathrm{Fe}, 0.12 \mathrm{O}, 0.016 \mathrm{C}$, $0.014 \mathrm{~N}, 0.021 \mathrm{~S}$, and balance Ti. The aging treatments were carried out at temperatures ranging from 426 to $600^{\circ} \mathrm{C}$ for $8 \mathrm{~h}$ under vacuum $\left(2 \times 10^{-4} \mathrm{~Pa}\right)$, followed by argon-assisted cooling to room temperature. To easily depict specimens aged at distinct temperatures, three digital numbers were assigned to the specimens with a capital letter "A" prefixed to the aging temperature. For instance, the A426 represented the specimen aged at $426^{\circ} \mathrm{C}$ for $8 \mathrm{~h}$, and the as-received specimen was designated by AR specimen. 


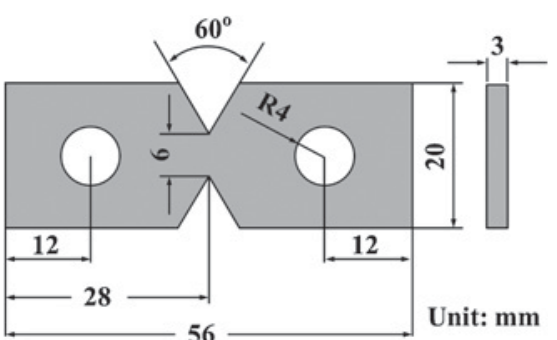

Fig. 1 Configuration of the double-edge notched specimen.

A Vickers microindentation hardness tester was used to determine the hardness of specimen under $300 \mathrm{~g}$ for $10 \mathrm{~s}$. To evaluate the influence of microstructure on the notch tensile fracture, the double-edge notched specimens, which were employed in a previous study and shown in Fig. $1,{ }^{17)}$ were used to determine the NTS values of the aged specimens. The use of such configuration could completely reflect notch brittleness of the tested specimens under tensile loading. ${ }^{17-20)}$ All of the notched specimens were prepared by electrodischarge wire cutting with a notch tip radius of approximately $100 \mu \mathrm{m}$. Notch tensile tests were conducted in laboratory air at a constant displacement rate of $1.0 \mathrm{~mm} / \mathrm{min}$. For high temperature tests, the specimens were placed in a furnance and heated from room temperature up to the preset temperature $\left(150,300\right.$ and $\left.450^{\circ} \mathrm{C}\right)$, then held at that temperature for $30 \mathrm{~min}$ before testing. The NTS results are presented as the average of at least three specimens for each condition. The fracture appearances of various specimens were examined using a scanning electron microscope (SEM, Hitachi S-4800) with particular attention paid on the variances in fracture features. For further microstructures observations, thin foil specimens, prepared by the twin-jet method using a solution of $35 \mathrm{ml}$ butyl alcohol, $60 \mathrm{ml}$ methyl alcohol, and $5 \mathrm{ml}$ perchloric acid at $-30^{\circ} \mathrm{C}$, were examined using a transimission electron microscope (TEM, JEOL 2010).

\section{Results and Discussions}

\subsection{Microstructure observation and hardness measure- ment}

Figure 2 shows the TEM bright-field images of the aged specimen. Evidently, aging at $371^{\circ} \mathrm{C}$ revealed $\alpha$ aggregates which were composed of acicular $\alpha$ precipitates, were formed by nucleating at precursory isothermal $\omega$ particles ${ }^{7)}$ and distributed sparsely within $\beta$ grains (Fig. 2(a)). In the aging at $426^{\circ} \mathrm{C}$ (higher than $673 \mathrm{~K}$ ), as reported by Furuhara et al. ${ }^{7)} \alpha$ precipitation first occurred preferentially at $\beta$ grain boundaries, followed by intragranular $\alpha$ precipitation with an elongated morphology. The elongated $\alpha$ precipitates aligned at the prior $\beta$ boundary and interlocked within the $\beta$ grains forming a basket-weave-like structure (Fig. 2(b)). For the specimen aged at $482^{\circ} \mathrm{C}$, platelet $\alpha$ precipitates were uniformly distributed within the matrix and outline the prior $\beta$ boundary (Fig. 2(c)). When the aging temperature was further increased, Widmanstätten $\alpha$ precipitation with an aligned $\alpha$ lath colony microstructure around the prior $\beta$ boundary was predominant instead of platelet $\alpha$ precipitates

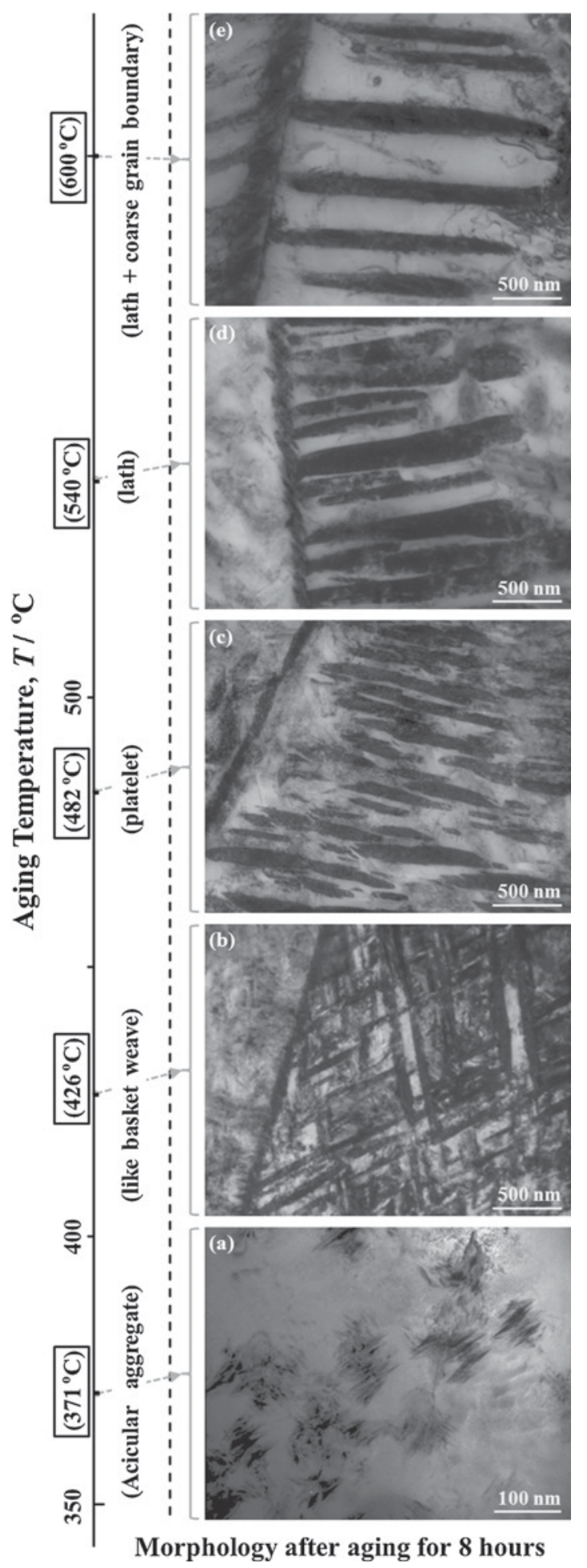

Fig. 2 TEM bright-field images of Ti-15-3 aged at distinct temperatures: (a) A371, (b) A426, (c) A482, (d) A540 and (e) A600.

after aging at $540^{\circ} \mathrm{C}$ (Fig. 2(d)). After aging at $600^{\circ} \mathrm{C}$, the thickness of grain boundary $\alpha$ layer became coarsening, and the distance among the aligned $\alpha$ lath colony increased (Fig. 2(e)).

The variation of hardness with aging temperatures in Ti15-3 is displayed in Fig. 3. It indicates that a marked increase in hardness to Hv 343 occurs after aging at $371^{\circ} \mathrm{C}$, which is associated with aggregation of acicular $\alpha$ precipitates in the matrix, as shown in Fig. 2(a). The peak hardness of Ti-15-3 


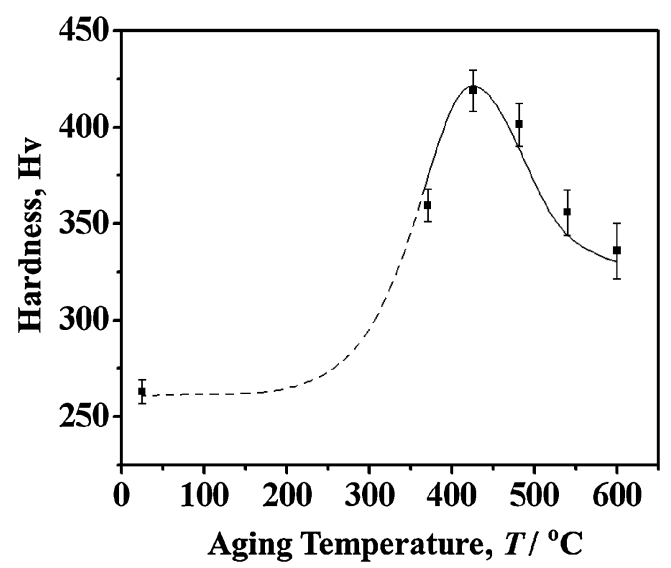

Fig. 3 Variation of hardness with aging temperatures in Ti-15-3.

reached $\mathrm{Hv} 420$ after aging at $426^{\circ} \mathrm{C}$ for $8 \mathrm{~h}$, which could be associated with the effective strengthening of sufficient amounts of acicular and elongated $\alpha$ precipates distributed uniformly within $\beta$ grains, as shown in Fig. 2(b). Owing to the coarsening of acicular $\alpha$ precipitates after aging at $482^{\circ} \mathrm{C}$, as shown in Fig. 2(c), the over-aged Ti-15-3 exhibited a marked decline in hardness. As the aging temperature was further increased to $600^{\circ} \mathrm{C}$, the size of $\alpha$ precipitates further coarsened and the density decreased (Fig. 2(e)). As a result, a relatively low hardness occurred in the over-aged specimen.

\subsection{Notch tensile test}

Figure 4(a) illustrates the variation of NTS values, determined at elevated temperatures, with aging temperatures for the Ti-15-3 specimens aged at distinct temperatures. When determined at room temperature $(R T)$ test, the NTS value decreased significantly before an aging temperature of $400^{\circ} \mathrm{C}$ and then increased markedly as the aging temperature was further increased. Because ultra-fine $\alpha$ precipitates appeared in the A371 specimen, as shown in Fig. 2(a), and could result in extensive cleavage-like fracture with worse NTS, ${ }^{20)}$ a deep minimum valley of NTS curve fitting around $300-400^{\circ} \mathrm{C}$ was consequently shown at $R T$ test. Also, the A426 specimen had a considerably lower NTS $(\sim 807 \mathrm{MPa})$ and showed the notch brittleness revealed by its lowest NTS. ${ }^{20)}$ It appeared that the acicular $\alpha$ precipitates, as shown in Fig. 2(b), played an important role in the reduction of NTS of A426 specimen. Additionally, the high NTS values were achieved in the over-aged specimens (A540 and A600) for the test at $R T$, which was associated with the effect of notch blunting before fracture ${ }^{20)}$ attributed to coarse Widmanstätten $\alpha$ precipitates, as shown in Figs. 2(d) and 2(e). It suggested that the over-aging treatment could raise NTS of Ti-15-3 alloy effectively. Moreover, the A426 (peak-aged) specimen with inferior NTS showed high notch sensitivity, partly attributed to the low tensile ductility of the specimens, ${ }^{20}$ ) while the notch sensitivity was diminishing either with increasing the aging temperatures or with increasing the test temperatures. Accordingly, the A426 specimen showed the high NTS in the test at $450^{\circ} \mathrm{C}$ owing to temperature effect alleviating the notch brittleness.

Besides, to facilitate the understanding of temperature effect on NTS, the variation of NTS values also displayed
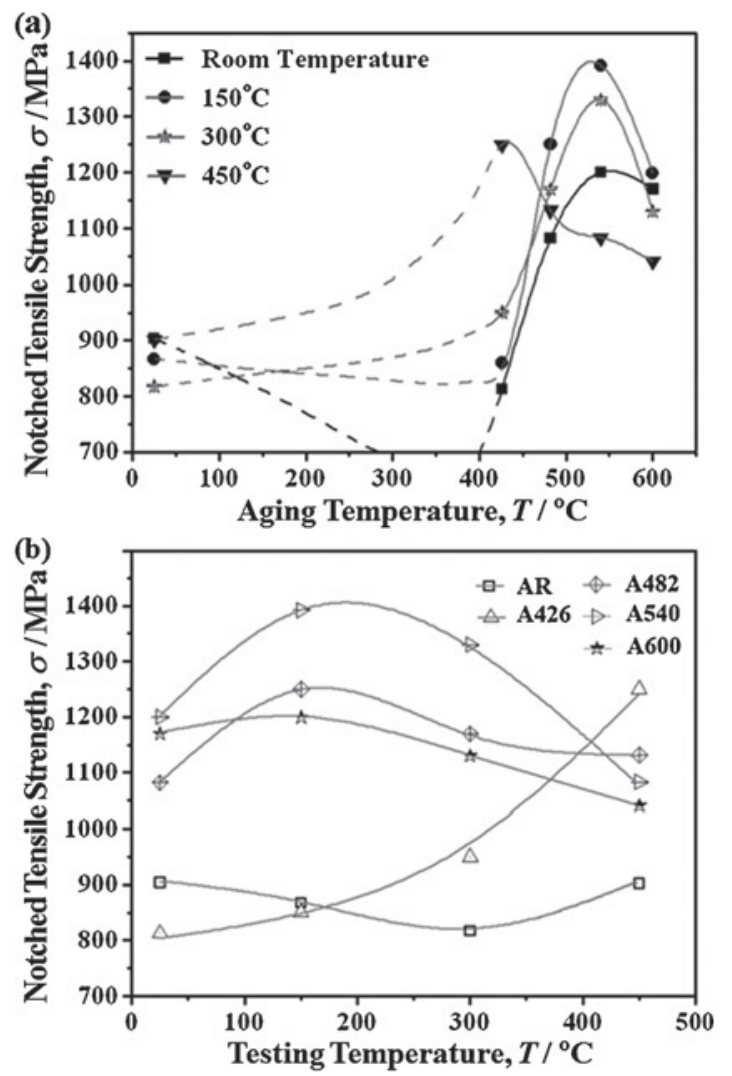

Fig. 4 (a) Variation of NTS values with aging temperatures for the Ti-15-3 specimens performing notch tensile test at elevated temperatures after aging. (b) Variation of NTS values with notch tensile test temperatures for the aged Ti-15-3 specimens tested at elevated temperatures.

with notch tensile test temperatures for the aged Ti-15-3 specimens, as shown in Fig. 4(b). As a whole, at ambient and elevated temperatures, the A540 specimen showed the comparatively higher NTS values than other aged specimens, except for the test at $450^{\circ} \mathrm{C}$. As mentioned above, the high NTS value of the aged specimens tested at $450^{\circ} \mathrm{C}$ is achieved by the A426 specimen. The NTS values of the A482, A540 and $\mathrm{A} 600$ specimens in the tests had a trend of increasing NTS from $R T$ to $150^{\circ} \mathrm{C}$, but a gradual decrease of NTS with further rising the test temperature. Nevertheless, the NTS of the AR specimen decreased with increasing test temperature and slightly rebounded in the test at $450^{\circ} \mathrm{C}$. Apparently, the temperature effect showed distinct influences on the NTS of the aged specimen at elevated temperature.

\subsection{Macroscopic SEM fractography}

In order to get an insight into the influence of temperature effect on the NTS of the aged specimens tested at elevated temperatures, SEM fractography was undertaken to examine the fracture feature. Figure 5 shows the macroscopic SEM fractographs of the variously aged specimens after notch tensile test at elevated temperatures. The variances of fracture appearances with aging temperatures were shown in rows, while the variances of fracture appearances with test temperatures were displayed in columns. The fracture appearances of the various specimens exhibited regions of slant fracture (SF), also known as shear lips, and flat fracture $(\mathrm{FF}){ }^{21)}$ Figure 5(a) displays the fracture appearance com- 


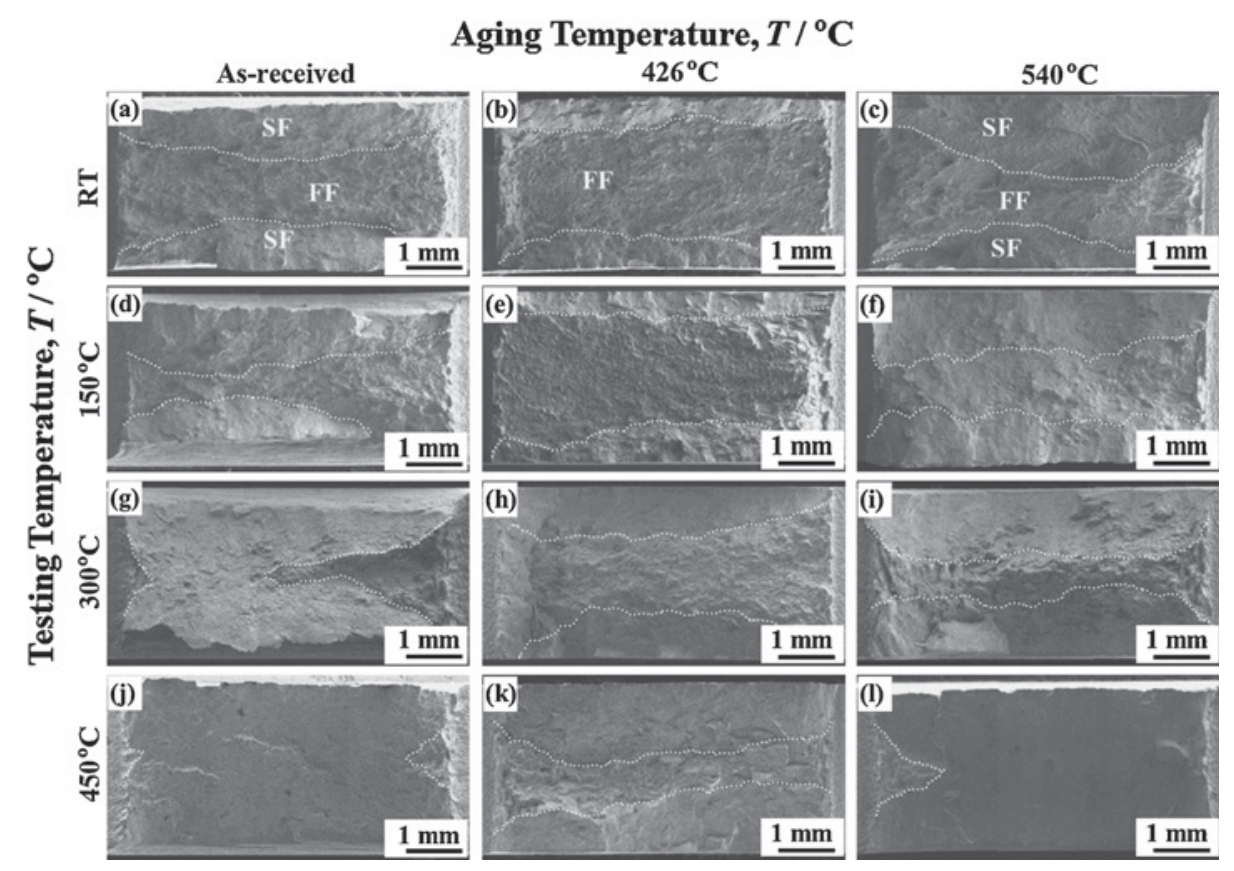

Fig. 5 The macroscopic SEM fractographs of the aged specimen tested at elevated temperatures, shown by using matrix-style arrangement. Here, aging temperatures are indicated on the top of photos, and testing temperatures are designated on the left side of photos. The intersection photograph of any row and any column represents the resultant fractograph for the aged specimen tested at a testing temperature. For instance, the macroscopic fractograph of the specimen aged at $540^{\circ} \mathrm{C}$ and then tested at $150^{\circ} \mathrm{C}$ is shown in (f).

prised of a certain extent of SF region in the AR specimen tested at $R T$, while the A426 specimen tested at $R T$ (Fig. 5(b)) exhibits extensive FF region, indicating the essentially brittle nature of these specimens and implying the inferiors NTS. In contrast, when the aging temperature is above $426^{\circ} \mathrm{C}$, the extent of SF region was larger than that of FF region and increased with increasing the aging temperatures for the aged specimens tested at $R T$. The lowered hardness and improved ductility promoted notch-blunting, leading to an increase of the SF region and improved NTS. In the A540 specimen tested at $R T$ (Fig. 5(c)), wide SF regions occupied both sides of the fracture surface after the crack propagated into the specimen. Such fracture appearance was associated with the high plastic deformation energy of the A540 specimen corresponding to the high NTS.

For tests at elevated temperatures, it appeared that an increase of the test temperature could lead to the increased ductility of the aged specimens corresponding to an increase of SF regions, particularly for the specimen tested at $450^{\circ} \mathrm{C}$. The A426 specimens tested at $150^{\circ} \mathrm{C}$ (Fig. $5(\mathrm{~d})$ ) also exhibited extensive FF region and showed low NTS as same as the A426 specimen tested at $R T$. While the test temperature further increased at/above $300^{\circ} \mathrm{C}$, the extent of $\mathrm{SF}$ region was larger than that of $\mathrm{FF}$ region and increased with increasing the test temperature of the A426 specimens, which was consistent with an increase of NTS. However, the variations of NTS values for AR and A540 specimens tested at elevated temperatures didn't appear a similar trend of the improved NTS with an increase of the SF region. Apparently, there is a limit to the improvement of NTS due to an increase of ductility, though better ductility is essential to high NTS. ${ }^{22)}$ In contrast, it suggested that the NTS of the A426 specimen with higher notch sensitivity could be improved effectively due to an increase of ductility during test at elevated temperatures. The improved NTS was not only partly attributed to better ductility, but also associated with microstructure, such as, the size, distribution and morphology of the $\alpha$ precipitates, the grain boundary $\alpha$ phase, and the grain size. ${ }^{11)}$ Moreover, the AR specimen showed an obvious reduction of the tested specimen thickness at elevated test temperatures, though the reduction of the specimen thickness tested at $450^{\circ} \mathrm{C}$ was smaller than the specimens tested at 150 and $300^{\circ} \mathrm{C}$, as shown in Figs. 5(a), 5(d), 5(g) and 5(j). This result implies the enhanced deformability of the AR specimen due to the elevated temperatures, which is indicative of the ease of deformation for the material used at elevated temperatures.

\subsection{Microscopic SEM fractography}

It was noted that the FF region is subjected to fracture resulted from deformation due to a two-dimensional strain state, and then the fractured appearance in the FF region was related to the microstructures of a given specimen. The microscopic SEM fractographs in Fig. 6 show the fracture features in the FF region of the variously aged specimens after notch tensile test at elevated temperatures, and the arrangement of the fractographs was laid out as well as Fig. 5. For the AR specimen fractured at $R T$, fine dimples mixed with cleavage-like fractures on certain grains were observed (Fig. 6(a)). The low NTS of the AR specimen seemed to be related to the presence of cleavage-like fracture ahead of the notch front and the ease of deformation during notch tensile test. It is to be noted that trans-granular quasicleavage fractures of the aligned separation appeared in the A426 specimen tested at $R T$ (Fig. 6(b)), while such fracture characteristics could be a result of the separation along $\alpha / \beta$ interfaces as happened in $\alpha+\beta$ titanium alloys. ${ }^{16,23)}$ With increasing aging temperature, ductile dimples became more 


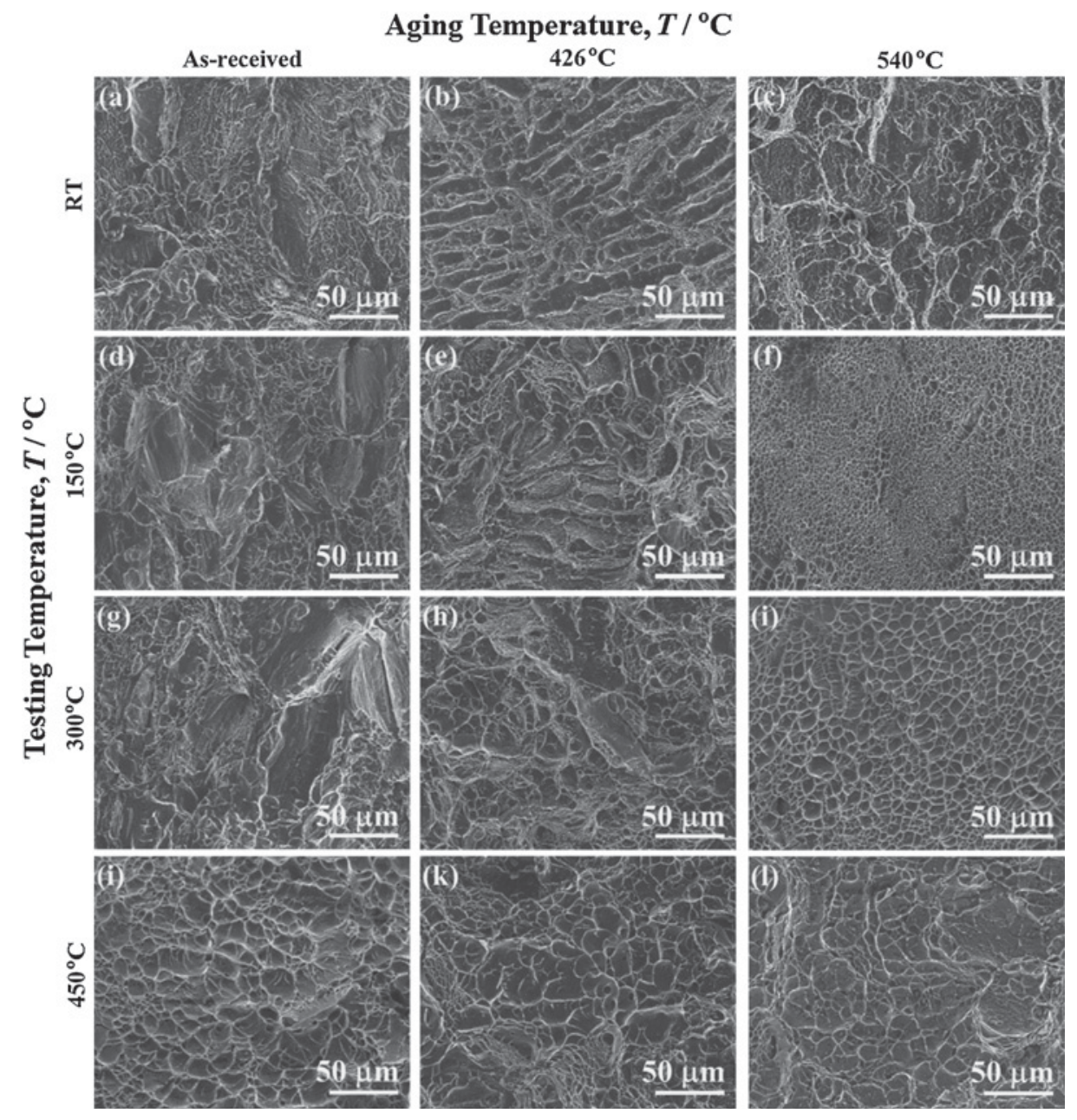

Fig. 6 The microscopic SEM fractographs of the aged specimen tested at elevated temperatures, shown by using matrix-style arrangement. Here, aging temperatures are indicated on the top of photos, and testing temperatures are designated on the left side of photos. The intersection photograph of any row and any column represents the resultant fractograph for the aged specimen tested at a testing temperature. For instance, the microscopic fractograph of the specimen aged at $540^{\circ} \mathrm{C}$ and then tested at $150^{\circ} \mathrm{C}$ is shown in (f).

and coarser in the tested notch tensile specimens. A mixed fracture mode, tear ridges and fine dimples within a coarse dimple, were found in the A540 specimen tested at $R T$ (Fig. 6(c)). Such fracture feature also showed the grain boundaries sliding and was associated with the coarse Widmansttäten $\alpha$ structure in the over-aged specimens, corresponding to the remarkably improved NTS.

When fractured at elevated temperatures, the aged specimens exhibited the increased plasticity associated with the increasing and coarsening dimple fracture, particularly for the specimen tested at $450^{\circ} \mathrm{C}$. In the $\mathrm{A} 426$ specimen tested at elevated temperatures, the trans-granular quasi-cleavage fracture disappeared gradually, and the fine dimple fracture increased progressively with increasing the test temperatures. At $450^{\circ} \mathrm{C}$, coarse dimples mixed with an increased extent of shear transverse to the colony boundaries were found in the A426 specimens (Fig. 6(k)). Such fracture feature was associated with the improved ductility, i.e., reduced quasicleavage fracture, and activated plastic deformation at elevated temperatures, corresponding to the improved NTS. Moreover, tiny and shallow dimples were found in the A540 specimen tested at $150^{\circ} \mathrm{C}$ (Fig. 6(f)), while such fracture feature reflected a relatively high NTS. The fracture feature became coarser and deeper with further increasing test temperatures, as shown in Figs. 6(i) and 6(1), resulting in the decline of NTS.

\subsection{Discussion}

In the previous study, ${ }^{20)}$ it pointed out that the higher NTS value can be associated with the improved fracture toughness and ductility at higher aging temperatures. Thus, for the test at $R T$, the macroscopic fracture appearance of the A540 specimen composed of wide SF regions exhibited a high degree of plasticity because of high NTS value corresponding to high fracture toughness. On the contrary, the macroscopic fracture appearance of A426 specimen appeared that the crack growth region was quite flat and related with the low fracture energy, resulting in deteriorated NTS. Besides, the A426 (peak-aged) specimen (Fig. 2(b)) possessed plenty of acicular and elongated $\alpha$ precipitates interlocked and distributed uniformly within $\beta$ grains. The forming basketweave-like structure inside $\beta$ grains could effectively retard the dislocation motions during deformation, as a result, the A426 specimen showed the peak hardness. On the other hand, the relatively high hardness of A426 specimen accompanied by restricted plasticity led to a premature 
failure in the notch tensile test and to the notch brittleness both corresponding to the extensive FF region (Fig. 5(c)) and the trans-granular quasi-cleavage fracture (Fig. 6(b)) in the specimen. The trans-granular quasi-cleavage fracture could be partly attributed to the higher difference in strength between the grain interiors and boundaries, resulting in the separation along $\alpha / \beta$ interface and the low NTS at $R T$ test. $^{16,23)}$

Moreover, it was reported, by Mora et al., ${ }^{24)}$ that a high orientation degree and a high density of $\alpha$ platelets contribute to the decrease of the ductility of the $\beta$-titanium alloy by decreasing the plastic strain region sizes and by increasing the void nucleation rate at $\alpha / \beta$ interfaces. In other words, if the orientation degree is high, the plastic strain region is smaller and voids, easily nucleated at the $\alpha / \beta$ interface, can propagate more easily, leading to fracture reached quickly and the ductility consequently smaller. When voids nucleated at the interfaces between the $\alpha$ laths and the beta matrix, stress and strain localization along the $\alpha / \beta$ interfaces led to separation of the $\alpha / \beta$ interfaces and to cracking of the $\alpha$ particles. Whereas, the restriction of plasticity would be released with an increase of test temperature, partly attributed to the reduced difference in strength between the grain interiors and boundaries as well as the softening of substance. Thus, the fracture dominated under high triaxiality could transit gradually to the fracture dominated under low triaxiality with test temperatures increased. Accordingly, the trans-granular quasi-cleavage fracture separated along $\alpha / \beta$ interface would be alleviated with increasing test temperatures and eventually transferred to the fine and shallow dimple fracture observed in the A426 specimen tested at $450^{\circ} \mathrm{C}$ (Fig. 6(k)), corresponding to the reduced notch brittleness or the improved NTS. The improved NTS of the A426 specimens (Fig. 4(b)) at elevated temperatures was also in response to a notable increase in the shear fracture regions (Figs. 5(h) and 5(k)). It was noted that the Widmanstätten $\alpha$ structure had high fracture toughness resulting from crack branching or crack deflection along lath boundaries in Ti-153 alloy, $\left.{ }^{9}\right)$ and the formation of continuous grain boundary $\alpha$ layer would promote grain boundary sliding for the specimens aged at/above $540^{\circ} \mathrm{C}$ during notch tensile tests, regardless of the solution temperature. ${ }^{20)}$ Such events were responsible for the significant improvement of NTS, and confirmed by the fracture feature of the A540 specimen tested at $R T$ (Fig. 6(c)). Furthermore, the microcracking at the interface of $\alpha$ and $\beta$, or shearing of ligaments between microcracks in a three dimensional manner also improved fracture toughness of titanium alloys in Widmanstätten $\alpha$ structure by causing stress relaxation. ${ }^{9)}$ Accordingly, crack deflection and microcrack formation occur more easily during fracture of the Widmanstätten $\alpha$ structure like coarse $\alpha$ structure while stress relaxation occurs more easily at elevated temperatures. It implies that extensive fine transgranular dimple fracture can be observed when the crack growth is either branching or deflecting and then transverse to the lath direction accompanied with plastic deformation at elevated temperatures. The more crack deflection and microcrack formation, the finer are the trans-granular dimples. Such event also suggests the better ability to resist crack growth and is confirmed by the observed fracture feature in the A540 specimen tested at elevated temperatures, particularly for the $\mathrm{A} 540$ specimen tested at $150^{\circ} \mathrm{C}$ showing the relatively fine dimples (Fig. 6(f)) and the peak NTS. It was revealed that higher NTS of the A540 specimen was consistent with the finer dimple fracture ahead of the notch front in the A540 specimen tested at elevated temperatures.

As for the fracture feature of the AR specimen, the fracture surface of $\beta$ titanium alloy is typically comprised of facetlike areas that display little plastic deformation prior to failure, ${ }^{11,12)}$ while the facetlike fracture is generally related to the pile-up of dislocations at the grain boundaries led to cracking. With the presence of sharp notch or crack, the cleavage-like fracture is likely to occur ahead of the notch front and then changed to shallow dimple features as the crack grew into the specimen. The cleavage-like fractures mixed with fine dimples on certain grains shown in the AR specimen tested under $300^{\circ} \mathrm{C}$ (Figs. 6(a), 6(d) and $6(\mathrm{~g})$ ) confirmed the event. Besides, the shearable $\omega$ precipitates generally formed in Ti15-3 alloy at $300^{\circ} \mathrm{C}^{7}$ ) were likely to appear in the $\mathrm{AR}$ specimen during the test at $300^{\circ} \mathrm{C}$, whereas the precipitates had lower resistance to dislocation movement. Thus, the declined trend of NTS could not be alleviated due to the $\omega$ precipitation during test at $300^{\circ} \mathrm{C}$ and continued to decline with the test temperature increased, but slightly rebounded following test at $450^{\circ} \mathrm{C}$. Fine and shallow dimples were observed in the AR specimen tested at $450^{\circ} \mathrm{C}$ (Fig. 6(j)), which was associated with the enhanced deformability and a little of fine $\alpha$ precipitation during the test at $450^{\circ} \mathrm{C}$. Since few $\alpha$ precipitates could form during test at $450^{\circ} \mathrm{C}$, the $\alpha$ precipitation was more or less benefical to strengthen $\beta$ matrix slightly. X-ray diffractometer analysis confimed the $\alpha$ precipitation in the $\mathrm{AR}$ specimen tested at $450^{\circ} \mathrm{C}$, not shown in here.

\section{Conclusion}

In this work, the influence of microstructures on the notch tensile strength of Ti-15-3 alloy was affected by the aging condition of the alloy, the presence of sharp notch, and the elevated ambient temperatures. It was concluded that the Ti$15-3$ alloy aged at $426^{\circ} \mathrm{C}$ formed the acicular $\alpha$ precipitation interlocked in a basket-weave-like structure and then had peak hardness but the inferior notch tensile strength at room temperature. The trans-granular quasi-cleavage fracture seperated along the $\alpha / \beta$ interface in the aged specimen accounted for the deteriorated NTS of the specimen compared with other aged specimen tested at room temperatures. As the aging and test temperature increased, the coarse Widmanstätten $\alpha$ in the specimen aged at $540^{\circ} \mathrm{C}$ was facilitated to perform high NTS owing to crack deflection or microcrack formation in Ti-15-3 alloy under $300^{\circ} \mathrm{C}$, while the improved ductility and notch blunting of the specimen aged at $426^{\circ} \mathrm{C}$ reduced the notch brittleness and resulted in a remarkably improved NTS tested at $450^{\circ} \mathrm{C}$. Based on the notch sensitivity of the specimens, Ti-15-3 alloy was, therefore, suggested not to be used in the peak-aged conditions with the presence of notch or crack at room temperature. However, the notch tensile strength of the specimen aged at $426^{\circ} \mathrm{C}$ was much higher than that of the 
other aged specimen tested at $450^{\circ} \mathrm{C}$. This result suggested that the basket-weave-like structure was more resistant to the softening of substance than the coarse Widmansttäten structure at $450^{\circ} \mathrm{C}$. For the as-received Ti-15-3 alloy, the notch tensile strength decreased with increasing test temperature because of the premature fracture due to the occurrence of cracks by dislocation pileups during the slip deformation and the ease of deformation during notch tensile test. Nevertheless, the notch tensile strength tested at $450^{\circ} \mathrm{C}$ slightly rebounded due to the little $\alpha$ precipitation during test.

\section{Acknowledgments}

The authors gratefully acknowledge the support of this study by the National Science Council of Republic China (NSC-99-2221-E-019-010-MY3).

\section{REFERENCES}

1) G. Terlinde and G. Fischer: Titanium '95 Science and Technology, ed. by P. A. Blenkinsop, W. J. Evans and H. M. Flower, (Institute of Materials, 1996) pp. 2177-2194.

2) C. Ouchi, K. Minikawa, K. Takahashi, A. Ogawa and M. Ishikawa: NKK Technical Review 65 (1992) 61-67.

3) T. Inaba, K. Ameyama and M. Tokizane: ISIJ Int. 31 (1991) 792-798.

4) M. Okada: ISIJ Int. 31 (1991) 834-839.

5) N. Niwa, A. Arai, H. Takatori and K. Ito: ISIJ Int. 31 (1991) 856-862.

6) T. Makino, R. Chikaizumi, T. Furuhara and T. Makino: Mater. Sci. Eng. A 213 (1996) 51-60.
7) T. Furuhara, T. Maki and T. Makino: J. Mater. Process. Technol. 117 (2001) 318-323.

8) S. J. Kim, B. H. Choe and Y. T. Lee: Proc. First Int. Symposium on Metallurgy Technology of Practical Titanium Alloys, (The Minerals, Metals \& Materials Society, 1994) pp. 167-172.

9) M. Niinomi and T. Kobayashi: ISIJ Int. 31 (1991) 848-855.

10) Y. Kawabe and S. Muneki: Beta Titanium Alloys in the 1990s, ed. by D. Eylon, R. R. Boyer and D. A. Koss, (The Minerals, Metals \& Materials Society, 1993) pp. 187-197.

11) H. J. Rack: J. Eng. Mater. Technol. 97 (1975) 330-337.

12) I. V. Gorynium, B. B. Chechulin, S. S. Ushkov and O. S. Belova: Met. Sci. Heat Treat. 16 (1974) 761-764.

13) M. G. Mendiratta, R. L. Goetz and D. M. Dimiduk: Metall. Mater. Trans. A 27 (1996) 3903-3912.

14) G. Said and S. Talas: Mech. Mater. 36 (2004) 1123-1128.

15) M. G. Mendiratta, R. L. Geotz and D. M. Dimiduk: Metall. Mater. Trans. A 27 (1996) 3903-3912.

16) K. J. Oswalt and A. Maloit: AFS Trans. 98 (1990) 865-877.

17) W. C. Chung, L. W. Tsay and C. Chen: Mater. Trans. 50 (2009) 544 550 .

18) L. W. Tsay, C. L. Hsu and C. Chen: ISIJ Int. 50 (2010) 128-132.

19) L. W. Tsay, Y. W. Wu and C. Chen: Metall. Mater. Trans. A 42 (2011) 3778-3784.

20) H. H. Hsu, Y. C. Wu and L. W. Tsay: Mater. Sci. Eng. A 545 (2012) 20-25.

21) W. T. Becker and R. Shipley: ASM Handbook, Vol. 11, Failure Analysis and Prevention, (ASM International, 2002) pp. 2897-2902.

22) H. Fukai, A. Ogawa and K. Minakawa: 10th world conference on Titanium, ed. by G. Lutjering and J. Albrecht, vol. V (2003) pp. 11471154.

23) L. W. Tsay, C. L. Hsu and C. Chen: Mater. Chem. Phys. 120 (2010) $715-721$.

24) L. Mora, C. Quesne and R. Penele: J. Mater. Res. 11 (1996) 89-99. 